\title{
"¿Quién no lo va a querer, si nos saca de muchos apuros?": Formas cotidianas de expresión de la devoción hacia el Niño Fidencio en la Ciudad de Saltillo
}

\author{
Francesco Gervasi*
}

\section{Resumen}

El presente artículo se enfoca en las formas de expresión cotidianas de la devoción hacia el Niño Fidencio en la ciudad de Saltillo. Los elementos más específicos que serán tratados son: las etapas a través de las cuales los entrevistados se han convertido en devotos "comunes" y en materias del Niño Fidencio; y las prácticas y experiencias concretas mediante las cuales estas personas expresan su devoción, en los momentos cotidianos de sus vidas. Los principales resultados destacan que el proceso a través del cual los entrevistados se volvieron devotos "comunes" y materias del Niño Fidencio viene vivido como una conversión que ha cambiado por completo sus vidas (mejorándolas); las prácticas concretas y cotidianas de expresión de la devoción, tanto en el caso de las materias como en el de los devotos "comunes", implican actividades individuales y colectivas mediante las cuales los entrevistados tienden, principalmente, a reafirmar su relación íntima, familiar y personal con el santo y a intentar solucionar sus problemas prácticos de salud (o de otro tipo) que surgen, cotidianamente, en sus trayectorias biográficas.

Palabras clave: Niño Fidencio, Saltillo, devoción, cotidianidad, prácticas individuales, prácticas colectivas

"Quem não vai adorar, se ele nos tira de muitos problemas?": Formas diárias de expressão de devoção à Criança Fidencio na Cidade de Saltillo

\section{Resumo}

Este artigo enfoca as formas cotidianas de expressão de devoção à Criança Fidencio na cidade de Saltillo. Os elementos mais específicos que serão abordados são: as etapas

* Universidad Autónoma de Coahuila. Email: francescogervasi@uadec.edu.mx 
pelas quais os entrevistados se tornaram devotos "comuns" e em matéria de Criança Fidencio; e as práticas concretas e experiências através das quais essas pessoas expressam sua devoção, nos momentos cotidianos de suas vidas. Os principais resultados destacam que o processo pelo qual os entrevistados se tornaram devotos "comuns" e "materias" de Criança Fidencio é vivido como uma conversão que mudou completamente suas vidas (melhorando-os); práticas concretas e cotidianas de expressão da devoção, tanto no caso das "materias", quanto nos devotos comuns, envolvem atividades individuais e coletivas, através das quais os entrevistados tendem, principalmente, a reafirmar sua relação íntima, familiar e pessoal com o santo e tentar resolver seus problemas de saúde práticos (ou outros) que surgem, diariamente, em suas trajetórias biográficas.

Palavras-chave: Criança Fidencio, Saltillo, devoção, cotidiano, práticas individuais, práticas coletivas

\title{
"Who will not love it, if he takes us out of many problems?": Everyday forms of expression of devotion towards the Child Fidencio in the City of Saltillo
}

\begin{abstract}
This article focuses on the everyday forms of expression of devotion to Niño Fidencio in the city of Saltillo. The most specific elements that will be addressed are: the stages through which the interviewees have become "common" devotees and materias of Niño Fidencio; and the concrete practices and experiences through which these people express their devotion, in the everyday moments of their lives. The main results highlight that the process through which the interviewees became "common" devotees and materias of Niño Fidencio is lived as a conversion that has completely changed their lives (improving them); concrete and everyday practices of expression of devotion, both in the case of the materias and in that of the "common" devotees, involve individual and collective activities through which the interviewees tend, mainly, to reaffirm their intimate, family and personal relationship with the saint and to try to solve their practical problems of health (or of another type) that arise, daily, in his biographical trajectories.

Keywords: Child Fidencio, Saltillo, devotion, everyday life, individual practices, collective practices
\end{abstract}

\section{Introducción: breve historia de la devoción, los objetivos y la justificación de la investigación}

Objetivo de este artículo es reconstruir las formas cotidianas de expresión de la devoción hacia el Niño Fidencio en la ciudad de Saltillo, enfocando la atención tanto en los devotos "comunes", como en las materias. El contexto de Saltillo se debe a tres principales motivos. Primero, porque este estudio se encuadra dentro de un proyecto de investigación más amplio, que arranqué en mi institución en enero de 2014 y cuyo objetivo 
principal es detectar, describir y analizar las formas de expresión de la diversidad religiosa presentes en la ciudad de Saltillo (Coahuila, México). El segundo motivo, que se relaciona de manera específica con la devoción objeto de la presente investigación, es que Saltillo representa una de las principales ciudades mexicanas en las cuales se han concentrado, desde su inicial difusión, las misiones fidencistas (ZAVALETA, 1998, p. 110). Finalmente, la decisión de estudiar las formas de expresión del fidencismo en esta ciudad, en lugar que en Espinazo (que es el principal, casi único, contexto en el cual, hasta ahora, la devoción ha sido estudiada), se debe a la intención de analizar un tema, hasta ahora, poco investigado con respecto a esta devoción, es decir: cómo los entrevistados la viven en los momentos ordinarios de sus existencias cotidianas, en lugar que en los extraordinarios. La justificación académica del presente estudio es que, sobre la devoción hacia el Niño Fidencio, existen pocas investigaciones (desarrolladas, principalmente, en Estados Unidos) ${ }^{1}$, las cuales se han enfocado en la reconstrucción de la historia del santo y en describir/ interpretar las formas de expresión de la devoción en Espinazo. En cambio, como mencionado arriba, no existen investigaciones que hayan concentrado su atención en cómo los fidencistas viven su devoción en los momentos cotidianos de su existencia, en cómo y por qué se volvieron devotos o materias del Niño Fidencio y en cómo han cambiado sus vidas después de haber experimentado este evento. Todos esos aspectos serán abordados en el presente artículo. Sin embargo, antes de empezar, vale la pena recordar, aun brevemente, en qué consiste esta devoción. José Fidencio de Jesús Constantino Síntora fue un curandero originario de Guanajuato, quien, en los primeros años del siglo XX, después de haberse mudado a Espinazo (pequeño ranchito que se encuentra en la línea que une el estado de Nuevo León con el de Coahuila, en el norte de México), se hizo muy famoso por haber sanado a miles de enfermos. Ya en vida, como consecuencia de estas capacidades curativas, las personas que lograba sanar y sus amigos y familiares lo empezaron a considerar santo. Después de su muerte, se difundió la creencia de que el espíritu de Fidencio se seguía encarnando en el cuerpo de algunos devotos (llamados "materias" o "cajitas") para seguir curando a la gente enferma. Hoy en día, el fidencismo, entendido tanto

Véanse, por ejemplo: BERLANGA, LARA, RAMÍREZ, 1999; GRAZIANO, 2007; QUIROS, 1991; ZAVALETA, 1998; ZAVALETA, SALINAS, SAMS, 2009; BROMLEY, D. G. y PHILLIPS, 2016. 
como devoción que como iglesia ${ }^{2}$, ha logrado difundirse en todo México (principalmente en el Norte) y, también, en Estados Unidos. Sus creencias se basan, en general, en una mezcla entre catolicismo ${ }^{3}$, chamanismo ${ }^{4}$ y espiritismo ${ }^{5}$, mientras que la mayoría de sus rituales giran en torno a prácticas de curación. Espinazo se ha convertido, cada vez más, en el principal lugar de culto de los fidencistas, tanto que, cada año, en octubre y marzo (meses que los devotos consideran como sagrados), se llena de fieles los cuales acuden para pedir un milagro, para curar sus enfermedades y para agradecer a Fidencio por algún milagro ya concedido.

En el presente texto, como ya mencionado arriba, no nos enfocaremos en cómo los fidencistas viven la devoción en Espinazo, sino en sus vidas cotidianas, en la ciudad de Saltillo. Más específicamente, los temas que abordaremos son: cómo, cuándo y por qué los entrevistados se hicieron devotos y materias del Niño Fidencio y cómo viven su devoción y su actividad de curanderos (materias) en sus vidas cotidianas.

Sin embargo, antes de presentar y discutir los resultados de la investigación, cabe mencionar que los próximos dos apartados se enfocarán, respectivamente, el primero en la descripción del método y de las técnicas utilizados para realizar la investigación de campo y, el segundo, en los "conceptos orientadores" (BLUMER, 1986, p. 148) que, de manera siempre flexible, han guiado, en sus distintas etapas, el presente estudio.

\section{Nota metodológica}

El enfoque metodológico de la presente investigación es de tipo cualitativo (SILVERMAN y MARVASTI, 2008), en el sentido que he utilizado instrumentos de recolección de la información no-estandardizados, el objeto de estudio está conformado por casos individuales y no representativos estadísticamente, y, sobre todo, el objetivo final de la investigación es construir modelos y tipologías (CORBET'TA, 2007, pp. 40-61). El objetivo

\footnotetext{
2 Una parte de sus seguidores ha creado la Iglesia Fidencista Cristiana (reconocida como asociación religiosa por el Gobierno mexicano, en 1993), pero hay muchas personas que, sin pertenecer a esta iglesia, se autodefinen fidencistas.

3 Porque algunas creencias pertenecen al catolicismo y porque la mayoría de los devotos se autodefine católica.

4 Principalmente por la capacidad del Niño Fidencio (y después de las materias) de detectar y curar el sufrimiento de las personas que acuden a las sesiones de curación.

5 Sobre todo, como consecuencia de la idea que el espíritu del Niño Fidencio se reencarna en algunos de sus devotos.
} 
principal que, como una brújula (GUIDICINI, 1971), ha guiado la actividad de investigación es el siguiente: describir y analizar cómo los devotos y materias del Niño Fidencio practican y experimentan esta devoción en sus vidas cotidianas en la ciudad de Saltillo, enfatizando, principalmente, elementos tales como los motivos y circunstancias que los llevaron a hacerse devotos o materias y las principales prácticas a través de las cuales viven su devoción y su actividad de curanderos (materias), hoy en día, en Saltillo. Para lograr lo anterior, hemos entrevistado ${ }^{6}$, desde mayo de 2018 hasta junio de 2019, a 11 devotos del Niño Fidencio presentes en la ciudad de Saltillo, de los cuales 5 son materias (4 hombres y una mujer) y 6 son devotos "comunes" (5 mujeres y un hombre). Hemos utilizado la entrevista semi-estructurada, con la recomendación de dejar que los entrevistados hablaran con la mayor libertad posible y que el entrevistador interviniera lo menos posible (para plantear las preguntas/temáticas y en aquellos casos en los cuales algo no quedaba claro). La técnica utilizada para seleccionar a los entrevistados es la de la "bola de nieve", que consiste en identificar los sujetos a entrevistar a partir de las personas ya entrevistadas (personas cuyas características cumplen con los objetivos de la investigación) (GOBO, 2007, p. 419). He utilizado esta técnica porque no existen estadísticas oficiales (CORBETTA, 2007, p. 258) de los devotos del Niño Fidencio que me permitieran identificar, catalogar y seleccionar a priori los sujetos a entrevistar. Vale también la pena recordar que no ha sido fácil conseguir los entrevistados, porque los fidencistas, frecuentemente, prefieren vivir su devoción de manera discreta y, por lo tanto, desconfían de quienes, por cualquier motivo, tiendan a amenazar esa manera tranquila e íntima de practicar su fe. Esta desconfianza se debe, principalmente, a los estereotipos que existen, en la sociedad mexicana, en contra de esta devoción, considerada, por muchas personas, como un conjunto de prácticas diabólicas y como una forma de brujería. Como resultado, hemos logrado entrevistar a 11 personas, pero hay que recordar que otras 6 se han negado. Sin embargo, estas 11 personas entrevistadas, como consecuencia del proceso de "saturación de las categorías" (GLASER y STRAUSS, 1967), representan una muestra idónea para poder llegar a construir, como mencionado arriba, un modelo teórico capaz de explicar cómo los fidencistas viven esta devoción en los momentos ordinarios de

\footnotetext{
6 Aprovecho esta nota para agradecer a los/las estudiantes de mi facultad que me han apoyado en la realización de las entrevistas: Juan Carlos Cepeda Rubio, Rubí Esmeralda Ríos Almeida, Xavier Hernández de la Fuente, Alonso Montenegro Martínez.
} 
su vida cotidiana. La generalizability de los resultados del presente estudio, como argumentado claramente por Gobo (2007, pp. 422-424), se basa en su "representatividad social" (y no estadística), en el sentido que el objetivo de la investigación no es saber cuántos devotos del Niño Fidencio viven su devoción de manera cotidiana a través de los elementos encontrados en el estudio de caso en Saltillo, sino detectar y clasificar estos elementos, para después poderlos utilizar, en otras investigaciones, como puntos de referencia flexibles o, como diría Max Weber, como "tipos ideales".

El método utilizado para analizar la información es el de la Teoría Fundamentada (GLASER y STRAUSS, 1967), según el cual la teoría puede ser construida, a través de un proceso flexible y multidireccional, utilizando como punto de partida la información encontrada y no como consecuencia de un proceso de deducciones.

Antes de terminar el presente apartado, vale la pena también destacar que, mientras que las entrevistas (es decir la fase de recolección de la información) las hemos realizadas entre algunos estudiantes (que he previamente entrenado sobre cómo actuar con los entrevistados) de la facultad en la cual trabajo y yo, de la codificación, decodificación e interpretación de las mismas me he encargado exclusivamente yo.

\section{Conceptos teóricos de referencia: religiosidad popular, conversiones religiosas, vida cotidiana y religión cotidiana}

En este apartado, definiré los principales conceptos teóricos que, en las varias etapas de la investigación, han sido utilizados como puntos de referencia, siempre flexibles y susceptibles de ser modificados, en su relación abierta con el fenómeno estudiado.

Siendo la devoción hacia el Niño Fidencio una forma de religiosidad popular, vale la pena empezar por ese concepto. La religiosidad popular hace referencia a aquella necesidad de sagrado que emerge por un "exceso de sentido que un sistema de creencias institucionalizado no logra mantener adentro de las fronteras de sus propios códigos simbólicos" (PACE, 2014, p. 53, traducción mía). En otras palabras, es una forma de religiosidad que los mismos creyentes administran de manera autónoma, es decir sin la intervención de las instituciones religiosas existentes (intermediarios), porque estas últimas no quieren o no pueden hacerse cargo de ella. El adjetivo popular, en este sentido, es utilizado, simplemente, para referirse a una forma 
de religiosidad administrada, justamente, por los mismos creyentes ${ }^{7}$. Sin embargo, en el caso de la devoción objeto del presente estudio, ese adjetivo puede ser utilizado también como sinónimo de forma de expresión religiosa "subalterna", es decir ejercida por las clases más pobres y vulnerables de la sociedad mexicana, en contraposición con la religiosidad (sobre todo católica) oficial de las élites. En este caso, entonces, la religiosidad popular representa, también, un importante recurso que tienen los grupos más vulnerables y desfavorecidos de una determinada sociedad, para superar los momentos críticos existenciales y, así, reafirmar su presencia en el mundo (DE MARTINO, 2003; DE MARTINO, 2004). Otras importantes características de la religiosidad popular que han sido útiles para la presente investigación, son las siguientes: sus creencias y prácticas son, generalmente, muy sincréticas (DE LA TORRE, 2012, pp. 509), la relación entre el devoto y el santo es de tipo familiar (GRUZINSKI, 1990) y contractual (RAMÍREZ, 2004, p. 36), la fe es concebida "como un instrumento que permite al individuo someter las leyes de la naturaleza para su beneficio" (NESTI, 1997, p. 57, traducción mía).

Teniendo en cuenta que, para interpretar el cambio de vida que los entrevistados experimentaron después de volverse devotos o materias del Niño Fidencio, utilizaré el concepto de "conversión", a continuación, vale la pena proponer una definición de este término. La conversión, desde un punto de vista sociológico, se refiere a: "un cambio radical, una transformación que casi siempre se describe en términos de un 'antes' y un 'después', hasta el punto de conducir a una especie de 'renacimiento' y a la construcción de una nueva identidad” (GIORDAN, 2009, p. 1, traducción mía). Según Gooren (2010, p. 48), la conversión representa una de las posibles dimensiones dentro de la actividad religiosa de un individuo, junto con la preafiliación, la afiliación, la confesión y la desafiliación”. Con base en esta distinción, según este autor, la conversión consiste en un: "cambio personal (radical) de la cosmovisión y de la identidad religiosa” (GOOREN, 2010,

Es importante aclarar que las materias no representan una figura jerárquica dentro de la devoción, sino unas personas que, a través de un contacto directo con la divinidad, recibieron ese don (sin necesitar la aprobación o legitimación de ninguna autoridad) y que se ponen al servicio de los demás devotos. Cualquiera, de un día para otro, puede decir que recibió este don. Entonces, desde este punto de vista, las materias, en lugar de contradecirla, tienden aún más a confirmar la dimensión muy desinstitucionalizada del fidencismo.

Con respecto a esta lectura, véanse, entre otros: A. NESTI, 1974; C. PRANDI, 1977.

9 Para una aplicación de este modelo al caso latinoamericano, véase el estudio de Lecaros (2017), quien utiliza el modelo de Gooren para analizar el caso de los “sin religión” en Lima. 
p. 49). Generalmente, en este "recorrido" (GOOREN, 2010), que funciona como un circuito complejo y dinámico (LECAROS, 2017, p. 5), es posible identificar un momento que los conversos mencionan como uno de los más importantes, es decir el turning point, que coincide con una etapa de la vida en la cual el sujeto logra solucionar, en su trayectoria biográfica, una crisis (LOFLAND y STARK, 1965, p. 870) importante, relacionando la solución del problema con la conversión.

Otro concepto que hay que definir es el de "vida cotidiana", que en el presente artículo utilizaré para referirme a aquel "conjunto de prácticas, ambientes, relaciones y horizontes de sentido en los cuales una persona está involucrada ordinariamente, es decir más frecuentemente y con la sensación de la mayor familiaridad, en una cierta etapa de su biografía" (JEDLOWSKI, 2005 , p. 20, traducción mía). Tomando como punto de partida la definición de "vida cotidiana", es importante delimitar también el concepto de "religión cotidiana" o "religión vivida", que podemos definir, en primera instancia, simplemente como el estudio de las maneras a través de las cuales "la religión se mezcla con la vida de la gente" (AMMERMAN, 2007, p. 5, traducción mía), enfocando la atención en aquellas prácticas y experiencias que realmente viven las personas religiosas y que se distinguen del conjunto de prácticas y creencias prescritas por una institución (MCGUIRE, 2008, p. 12). Algunos elementos importantes de la definición de "religión cotidiana" que tomaré en cuenta en este texto son: que es un tipo de religiosidad que se experimenta y practica en los momentos ordinarios de la vida y en espacios que "normalmente no son designados como institucionalmente religiosos” (AMMERMAN, 2013, p. 324, traducción mía), que ocurre afuera de las instituciones y de los eventos organizadas, y que tiene que ver tanto con en el ámbito privado como con el público (AMMERMAN, 2007, p. 5) de las personas involucradas.

Después de estas reflexiones de tipo teórico, en los próximos dos apartados presentaré los resultados hallados en la investigación de campo. Más específicamente, en el primero, concentraré la atención en los elementos que han llevado a los entrevistados a volverse (y a seguir siendo hasta la fecha) devotos y materias del Niño Fidencio y, en el siguiente, me enfocaré en los aspectos más importantes que caracterizan la manera cotidiana de vivir esta devoción en Saltillo. 


\section{4. "Convirtiéndose en devotos y materias del Niño Fidencio"10: reconstrucción de los eventos y de los motivos que llevaron los entrevistados a tomar esta decisión}

Las preguntas a las cuales intentaré contestar, en este apartado, son las siguientes: ¿en qué momento y por qué los entrevistados se hicieron devotos y materias del Niño Fidencio? ¿cuáles fueron los eventos y etapas que los llevaron a tomar esta decisión? ¿por cuáles razones siguen siendo devotos y materias del "Cristo de Espinazo" ?

Vamos a empezar concentrando la atención en el proceso a través del cual los entrevistados se convirtieron en devotos "comunes", recordando que, en esta parte, serán tomadas en cuenta también las materias porque, además de tener este papel, son al mismo tiempo devotos del Niño Fidencio. Tanto en el caso de los devotos "comunes" como en el de las materias, la causa desencadenante ${ }^{12}$ ha sido, generalmente, un problema de salud personal o de algún familiar, como se puede apreciar en los dos próximos testimonios:

1) yo me ponía muy enfermo, llegaba el día que yo entraba con nervios, nada me controlaba, siempre estaba enfermo e intranquilo, si no me componía de una cosa me enfermaba de otra, me la vivía enfermo. Un día mi mamá me invitó con una materia del Niño. Fuimos con esa materia y al ir sentí como me estremecí con la fuerza del Niño, al momento que me estremezco yo me retiro y, de ahí, ya no tuve más problemas (Pablo ${ }^{13}$, hombre, 40 años, materia y devoto del Niño Fidencio desde hace 17 años)

2) Bueno te digo, hace 5 años yo estuve muy enferma, me hicieron análisis de todo y nunca me hallaron nada, hubo un vecino de por ahí que me dijo: “¿Sabes qué? Te voy a llevar con esta persona para que los ayude y fue allí el momento en que yo empecé a conocerlo a él...Me hice devota porque me cumplió. Pues, él me sanó, por medio de mi padre Dios y El Niño me

10 Aquí estoy parafraseando el título del clásico estudio sobre conversiones religiosas de LOFLAND y STARK (1965).

11 Así es llamado por algunos de sus devotos.

12 Que representa, por lo tanto, un momento de ruptura dentro de las actividades rutinarias de sus vidas cotidianas. Después de esta "ruptura de la cotidianidad" (JEDLOWSKI, 2005, p. 26, traducción mía), como veremos a continuación, nuestros entrevistados, gracias al encuentro con la devoción, logran nuevamente instaurar el proceso de "domesticación de la vida" o "esterilización del asombro", cuyo resultado final es la creación de aquel contexto de familiaridad que, típicamente, caracteriza la vida cotidiana (JEDLOWSKI, 2005, pp. 24-25, traducción mía).

13 Los nombres de los entrevistados han sido modificados para tutelar su privacidad. 
sanaron y aquí estoy (Lucía, mujer, 39 años, devota del Niño Fidencio desde hace 5 años).

En estos dos testimonios se mencionan problemas de salud que vienen resueltos gracias a la intervención de alguna materia del Niño Fidencio, presente en Saltillo. Utilizando las categorías analíticas desarrolladas para interpretar los procesos de conversión, ese primer encuentro coincide con la fase que Lofland y Stark (1965, p.870) definen como turning point, es decir un momento biográfico crucial, en el cual el entrevistado logra solucionar un problema considerado muy grave en su vida. Como en el caso de las conversiones, después de este primer acercamiento, tanto los devotos "comunes" como las materias necesitan de un proceso que podríamos definir de "experimentación" de la devoción (LOFLAND y SKONOVD, 1981), para poderse definitivamente convencer que ella representa la mejor opción en sus vidas. Utilizando las categorías de Gooren (2010, pp. 48-49), estos dos momentos coinciden con el pasaje de la preafiliación a la conversión (pasando por la afiliación). La experimentación, en los relatos de los entrevistados, consiste en un periodo durante el cual ponen a prueba las capacidades milagrosas del santo y, después de haber experimentado y haberse dado cuenta que el santo sí cumple, racionalmente (BOUDON, 1989; BOUDON, 2000) toman su decisión de seguir siendo devotos, como se puede ver en los dos próximos testimonios:

1) Porque él..uhmmm, él es bien poderoso. Es grandioso. ¿Quién no lo va querer si nos saca de muchos apuros? Saca de muchos apuros y pues lo queremos mucho, lo apreciamos y yo le doy gracias a Dios (Fernanda, mujer, 64 años, devota y materia del Niño Fidencio desde hace 7 años).

2) Me convencí que el Niño era lo mejor para mí, más que nada, por los milagros que nos hizo. Por ejemplo, cuando mi niña nació, ella tomaba solo líquidos, no quería comer. No le daban comida, porque ella tenía que tomar media onza, la tomaba y la vomitaba. El Niño Santo me ayudó y mi hija llegó a tomar una onza en un día. Además, yo me embaracé con dispositivo y el dispositivo no le hizo daño a mi niña para nada, salimos ella y yo bien, ni se le encarnó ni nada, el dispositivo andaba nomás nadando. Estoy muy agradecida con el niño y primeramente con mi Dios (Alicia, mujer, 39 años, devota del Niño Fidencio desde hace 13 años).

En ambos casos, lo que convence a estos dos entrevistados (y también a todos los demás) es que la devoción logra satisfacer una necesidad de 
sagrado toda centrada en una visión práctica y mundana del hecho religioso, esta "religiosidad del yo" (NESTI, 1997, p. 70, traducción mía) cuya principal finalidad es salvarse aquí y ahora (HERVIEU-LÉGER, 1996, 217). Los entrevistados demuestran ser personas que, en el mercado de los bienes religiosos latinoamericano (CHESNUT, 2003), después de haber intentado solucionar sus problemas a través de diferentes opciones, eligen de manera racional al fidencismo, simplemente porque este último logra satisfacer sus necesidades mejor que las demás. Como mencionado por Chesnut (2003, p. 3, traducción mía), los devotos latinoamericanos, después de siglos de monopolio católico, tienen hoy en día "la libertad de elegir entre cientos de productos religiosos que mejor se adaptan a sus necesidades espirituales y materiales". Lo anterior aplica también a la medicina que, después de haber demostrado su incapacidad para solucionar el problema del cual sufre el entrevistado, viene sustituida por la opción fidencista, como es posible apreciar en el próximo relato:

Yo me sentía mal con muchas enfermedades, ya cuando fuimos al hospital me empezaron a analizar y me dijeron que no estaba enferma. Decían que estaba loca y hasta me internaron en el CESAME (Centro Estatal de Salud Mental). Salí, me seguía sintiendo mal y fue hasta que fui con el Niño, que me empezó a ayudar. (Lucía, mujer, 39 años, devota del Niño Fidencio desde hace 5 años).

Tanto las materias como los devotos "comunes" reconocen que el encuentro con el Niño Fidencio ha representado, en sus vidas, un momento "de ruptura" (BERGER y LUCKMANN, 2001, p. 198) a partir del cual, como pasa en las conversiones religiosas, empezaron reinterpretar sus biografías como divididas entre un "antes del encuentro" caracterizado principalmente por experiencias negativas, y un "después", en el cual, en cambio, destacan casi exclusivamente los aspectos positivos que la devoción ha implicado en sus vidas, como se puede notar en los dos próximos testimonios:

1) Para mí, mi vida ha mejorado. Empecé a los 13 años y a la fecha de mis 26 años no conozco el antro, no sé qué se siente prender un cigarro, he probado alguna bebida, pero al grado de perderme, no, las veces que he probado cada que hay una fiesta o así en familia. (Francisco, hombre, 26 años, materia y devoto del Niño Fidencio desde hace 13 años).

2) Mi vida ha mejorado mucho. Antes como que era más rebelde, a los 15 
años era más rebelde, pero el Niño como que habla contigo y te pone altos, trata de mejorar las cosas y ya cambié mucho. Ya me llevo mucho mejor con mi mamá, con mi familia y sí, mi vida cambió para bien (Vanessa, mujer, 20 años, devota del Niño Fidencio desde hace 5 años).

En otras palabras, la devoción cumple con las expectativas de los entrevistados no solo en el sentido de que los ayuda a solucionar sus problemas prácticos (de salud o de otro tipo), sino porque ella implica, también, como en el caso de las conversiones, una reorganización más amplia de sus existencias (HERVIEU-LÉGER, 2003, p. 103).

Después de esta reconstrucción de las principales etapas a través de la cuales las personas se convierten en devotos del Niño Fidencio, conviene, ahora, concentrar brevemente la atención en las especificidades que caracterizan el camino que ha llevado a los entrevistados a volverse materias, utilizando la siguiente descripción, muy parecida, aun con las diferencias circunstanciales que caracterizan las diferentes experiencias biográficas de los diferentes entrevistados, a las demás:

Yo tenía 17 años. Entonces, pues, ya fue cuando empecé como quien dice pues el proceso, porque pues es todo un proceso vaya, es una preparación. Se llama como que, sí, o sea, es el nombre que le dan, preparación. Las demás materias te invitan a que vayas a varias sesiones de las que hacen, dentro de esas sesiones empiezas a hacer el proceso que incluye baños, en el sentido que tienes que bañarte tres días con la misma agua, la dejas así toda la noche y al otro día te bañas en la mañana o ese día en la noche, con el agua esa, y le ponen ciertas lociones también, como la loción de los Siete Machos. Y pues a mí me recomendaron una que se llama flor de naranjo, que era la que yo le ponía y conseguía tres flores de campo y esa era el agua con la que me bañaba. Eso fue cuando empecé el proceso. Después, ya cuando llevas un tiempo, dentro de las sesiones te inyectan como quien dice, como si fuera un tipo de "don", vaya para que pues empieces a ver tú ya más allá, o sea empiezas ya con los poderes de videncia Pues, ya cuando estás en ese proceso, dejas que, o sea, que el niño baje en ti ¿no? Haces una visita a Espinazo Nuevo León, ahí haces como una... es una manda que le entregas al niño como pues entregando ya tu alma a él. Entonces, ya cuando pues se termina ese proceso, llega tu momento de tu coronación que es en el mes de marzo o en el mes de octubre, que son los meses de las fiestas en Espinazo. Y ya, dentro de tu coronación, pues te presentan, ahora sí, como quien dice, a la sociedad ya como una materia. Cuando estaba en ese proceso, pues, al momento de iniciar, sentía como un hormigueo en los pies y empezaba a sentir el hormigueo por todo el cuerpo, luego llega un momento en el que ya 
no sabes nada, solo te duermes y ya cuando pues te despiertas entonces es cuando ya te empiezan a platicar de que hiciste curaciones, todo eso. De un principio, cuando empiezas a ser materia, la bajada del Niño empieza a pasar en cualquier momento. O sea, de repente me pasaba de que andaba en el centro y empezaba a sentirme así. El primer síntoma que tienes es que sientes mucho asco y empiezas como a devolver todo lo que tienes en el estómago, porque pues el estómago debe de quedar vacío. Incluso hay materias que, he sabido yo, han muerto de infartos por la energía que reciben. Es que, en un principio, no lo controlas porque pues eres como que, estás en un proceso de evolución, algo así, y no lo controlas. Después, ya llega un momento en el que ya, o sea ya lo controlas totalmente, o sea ya es fácil, pero cuando ya está a punto de entrar el niño es cuando empiezan los cantos, las oraciones, y ya es cuando como que abres totalmente tu cuerpo y es cuando él entra (Roberto, hombre, 25 años, materia y devoto del Niño Fidencio desde hace 8 años).

Esta larga descripción es muy interesante porque nos permite entender, a través de las palabras del entrevistado, cómo se viven las diferentes etapas a través de las cuales una persona se convierte en materia. Como se puede notar, el inicio del proceso es vivido como una iluminación irracional (que ocurre en un momento difícil de la vida de los entrevistados), en la cual el Niño Fidencio escoge a la materia, quien tiene, en este primer momento, un papel exclusivamente pasivo, el cual perdura durante las etapas iniciales de la experiencia, caracterizadas por la incapacidad, por parte del elegido, de controlar el don que recibió. Después, el don recibido de manera irracional va desarrollado y racionalizado (para poder ser controlado) a través de un proceso que, el mismo entrevistado, define como una preparación, en la cual destacan principalmente los rituales de purificación logrados a través de baños en agua, mezclada con lociones. En otras palabras, la dimensión irracional debe de ser absorbida a través de una especie de rutinización del carisma (con el líder carismático en vida), que convierte el don en algo controlable y utilizable cuando se necesite. Igual que en el caso de los devotos "comunes", el convertirse en materias representa, para los entrevistados, un momento de ruptura crucial (BERGER y LUCKMANN, 2001, p. 198) en sus biografías, aún más cuando el elegido se convierte en un curandero profesional, es decir una persona que vive de sus curaciones, como se puede apreciar en el próximo testimonio: 
En ese entonces yo trabajaba en una maquiladora en Ramos, se llamaba Tecnotrim, desde hace 10 años. Y ahí llegó el Niño y me dijo que ya, que era tiempo de servirle de lleno, que no trabajara, que se iba a encargar de mí, que no me iba a dar riqueza pero que no me dejaría sin solvencia económica para mis hijos. Yo me sentí angustiado, mi angustia era de no solventarme, no tener que comer, todo eso me mortificaba. Entonces, cuando el Niño me dice que ya debo servirle a él, yo no tenía gente y yo le preguntaba al Niño si con lo poco o mucho que me dieran iba a completar y me dijo que él me iba a solventar. ¿De qué manera? Yo no lo iba a ver, pero lo iba a saber y hasta ahorita así ha sido. (Pablo, hombre, 40 años, materia y devoto del Niño Fidencio desde hace 17 años)

El momento de ruptura representa, al mismo tiempo, un cambio positivo en la vida de las materias, quienes aprecian sobre todo la posibilidad de poder curar, aquí y ahora, a las personas necesitadas, como se puede notar en el siguiente fragmento:

Dentro de la iglesia lo bonito es la oración, la presencia de Dios. Dentro de la iglesia ves personas que no pueden caminar, sufren algún malestar o dolor, por ejemplo, que van al doctor y no les encuentra remedio. Cuando conocí al Niño, iba gente con muletas, los sobaba y salían caminando. Iba gente con férula en los brazos, los curaba y se las quitaba, iba gente con collarines que no podían mover el cuello, los curaba, había gente que no veía y les ayudaba a empezar a ver. Mi motivación, ahora, es esta, que gracias al Niño puedo ayudar a la gente que necesita curación, ayudar en la enfermedad, al ver como el Niño puede ayudar a los demás. (Francisco, hombre, 26 años, materia y devoto del Niño Fidencio desde hace 13 años).

Terminando este apartado, cabe destacar que tanto los devotos "comunes" como las materias sostienen que el haber encontrado al Niño Fidencio ha representado el momento más importante de su experiencia religiosa $y$, en general, de su trayectoria biográfica, sosteniendo que ese encuentro ha implicado, en sus existencias, un verdadero proceso de construcción de "sí mismos" (HERVIEU LÉGER, 2003, p. 104), en el cual los entrevistados contraponen "un antes trágico, desesperante o simplemente mediocre, a un después caracterizado, al contrario, por una plenitud de sentido” (HERVIEU LÉGER, 2003, pp. 104-105). 


\section{Prácticas y experiencias cotidianas a través de las cuales los devotos y las materias del Niño Fidencio expresan su devoción en Saltillo}

En este apartado, concentraré la atención en cómo los devotos comunes y las materias viven esta devoción en los momentos ordinarios de su vida cotidiana. Empezaremos por los devotos "comunes" (incluyendo, también en este caso, a las materias), recordando que todos los entrevistados tienden a destacar la dimensión personal y autónoma (HERVIEU LÉGER, 2003, p. 131) de esta devoción, sosteniendo que:

1) Mi devoción primeramente vive en mi corazón, en mi mente y en todo mi cuerpo" (Lucía, mujer, 39 años, devota del Niño Fidencio desde hace 5 años).

2) Mi devoción vive en mi corazón, este... vive también en el templo donde hay curación porque no donde quiera hay o sea hay que buscar un templo donde ahí está el Niñito (Jéssica, mujer, 52 años, devota del Niño Fidencio desde hace 5 años).

Las maneras individuales de vivir la devoción se centran, principalmente, en la comunicación directa, personal, casi familiar (GRUZINSKI, 1990) y cotidiana con el santo, como se puede apreciar en el próximo testimonio:

Tengo un altar dedicado al Niñito. Lo puse porque quería tener su presencia en mi casa, por sentirlo, voltear en las mañanas y, primeramente, Dios, cuando salgo, le hablo y le digo: "ya me voy Niñito Santo, cuídame y al rato regreso" (Alicia, mujer, 39 años, devota del Niño Fidencio desde hace 13 años).

Los entrevistados, generalmente, tienen los altares (de diferentes tamaños) del Niño Fidencio ${ }^{14}$ en sus casas, en un cuarto totalmente dedicado al santo o, a veces, en las cocheras. En ambos casos, se trata de altares domésticos que dan la posibilidad a los creyentes de vivir su devoción en cualquier momento de su vida cotidiana, hablando con el santo, contándole sus problemas, haciéndole sus peticiones o, simplemente, rezándole. En los altares, conjuntamente a la imagen del Niño Fidencio (y, muy frecuentemente, de otros santos), hay

14 Es interesante recordar que, en muchos casos, en el mismo altar, los devotos tienden a juntar el Niño Fidencio con otros santos, algunos reconocidos por la iglesia católica (como, por ejemplo, la Virgen de Guadalupe y San Judas Tadeo) y otros no (como en el caso de Santa Aurorita o San Pancho Villa). 
que poner agua, velas blancas, incienso y flores. Además, dependiendo del diferente periodo del año, se cambian los colores del mismo altar, como se puede apreciar en el próximo fragmento:

Le ponemos un vaso de agua, una vela blanca, flores. Ahora el altar está blanco porque pasó la resurrección, dependiendo del tiempo de las fiestas es el color del altar. Copas de agua para la bendición de espíritus, veladoras que la gente viene a pedir, el altar debe de estar siempre limpio y ordenado (Francisco, hombre, 26 años, materia y devoto del Niño Fidencio desde hace 13 años).

Otro aspecto importante que caracteriza las formas cotidianas individuales de vivir la devoción es la cuestión de las peticiones que se hacen al santo. Los devotos las dirigen, autónomamente y directamente, a las varias imágenes o estatuas del Niño Fidencio presentes en sus casas, en sus contextos domésticos, y tienen que ver, principalmente, con cuestiones de salud o con otros problemas, siempre muy prácticos, de la vida cotidiana, como se puede apreciar en los próximos dos testimonios (de una materia y de una devota común):

1) Sobre todo le pido mucha salud, tranquilidad, fortaleza, bendiciones para mí, para mi familia, para la gente (Mario, hombre, 29 años, materia y devoto del Niño Fidencio desde hace 33 años).

2) Que nos ayude en cuestión de estar bien, salud, que mi familia siempre esté unida. De que me ayude a realizar sueños, como los estudios, pues ayudarnos a seguir adelante para que no venga nada en contra de nosotros. Esas personas que nos desean mal o que nos hagan el mal, que no nos llegue. (Vanessa, mujer, 20 años, devota del Niño Fidencio desde hace 5 años).

La devoción se vive también en algunos eventos colectivos que los devotos llaman "misas" (durante las cuales, generalmente, se realizan también los rituales de curación), que se celebran, periódicamente, en las casas de las materias presentes en Saltillo. A continuación, dos testimonios en los cuales se describen, respectivamente, en el primero los preparativos de estas reuniones colectivas, y en el segundo los principales rituales que en ellas se realizan:

1) Antes de empezar nos ponemos a orar, nos ponemos en las manos de Dios y limpiamos todo lo malo que podamos traer. Hay cantos antes de que empiece todo. Se enciende la luz para que ya la persona que va a bajar al Niño empiece a relajarse un poco más. Usamos la loción de los siete machos, que es una loción que usamos nosotros para despojar las malas vibras que traigamos 
para empezar a trabajar. Hay muchas esencias que empezamos a mezclar también. (Lucía, mujer, 39 años, devota del Niño Fidencio desde hace 5 años).

2) Los miércoles vamos a las bendiciones. Bueno, primeramente Dios nos vamos de blanco, es como por limpieza o pureza, bien aseados, llegamos, esperamos que se junte la gente para empezar el rosario ${ }^{15}$, empieza la materia y termina el rosario, se concentra cuando llega el Niño, llega el Niño, les da la bienvenida a los misioneros, les da su limpia a veces con un limón, a veces nomás con las manos con la energía del Niño, a veces con un ramito, ruda o romero o así hierbitas. (Alicia, mujer, 39 años, devota del Niño Fidencio desde hace 13 años).

Esos encuentros se parecen un poco a las misas católicas, pero, al mismo tiempo, se diferencian de ellas por muchos motivos, como es posible apreciar en el próximo testimonio de una materia:

Los domingos realizamos misas en honor a Dios y al Niño Fidencio, pero, en lugar de compartir hostia y vino, se comparte pan de trigo y jugo de uva, en representación de la última cena. En nuestra iglesia hay bodas, bautizos, casamos gente, así como lo hizo en vida y lo sigue haciendo Fidencio, hay sacramentos, como lo dije, el Niño Fidencio, a las personas mayores, les da los sacramentos, ya sea comunión o confirmación. Cuando es día de sesión se ofrece el rosario y la gente que viene a curación ofrece cantos (Francisco, hombre, 26 años, materia y devoto del Niño Fidencio desde hace 13 años).

Además, durante estas "misas", se leen fragmentos de la Biblia y, también, del libro del Niño Fidencio. Sin embargo, el objetivo final de estas reuniones es favorecer, colectivamente, la bajada del Niño en las materias, para realizar las curaciones. En cuanto a los objetos utilizados en estos eventos colectivos, los más importantes son: flores, agua, varios tipos de lociones, velas, incienso, aceites, cuyo objetivo es, principalmente, favorecer la purificación de los asistentes y del lugar, antes y durante las celebraciones.

Pasando a las materias, como en el caso de los devotos comunes, los entrevistados tienden a destacar que su misión y devoción las viven en todos los ámbitos de su vida cotidiana y a través de diferentes actividades, como se puede apreciar en el próximo fragmento:

15 Vale la pena mencionar que el rosario, en cuanto objeto, es el mismo que usan los católicos. Lo que cambia, en el caso de los fidencistas, son las oraciones que, en esta devoción, tienen como principal protagonista al Niño Fidencio. Al mismo tiempo, cabe aclarar que los devotos realizan también muchos rezos dedicados a santos católicos porque, como lo he mencionado, la mayoría se autoidentifica con esta confesión religiosa. 
La devoción la vivo en todo lo que yo hago. Yo siento que es parte del fidencismo, por ejemplo, dar un consejo a la gente en la calle. La vivo todos los días porque particularmente el altar está en mi casa, donde vayas encontrarás algo del Niño Fidencio y yo vivo y comparto donde quiera al Niño, a veces una estampita, camino al trabajo se me viene a la mente una alabanza o un canto al Niño o alguna oración. Lo vivo a diario (Francisco, hombre, 26 años, materia y devoto del Niño Fidencio desde hace 13 años).

Pero ¿cuáles son las actividades más específicas y concretas que realizan las materias en los momentos ordinarios de sus existencias? Como en el caso de los devotos comunes, también las actividades de las materias pueden ser divididas entre las de naturaleza colectiva y las individuales. Las primeras incluyen los rituales de curación realizados en sus casas, la celebración de las "misas" (siempre en sus casas, utilizadas como templos) y, en algunos casos, también de algunos sacramentos (bautizos, confirmación, matrimonios), mientras que las individuales consisten, sobre todo, en rezar y evocar al Niño Fidencio todas las noches, para mantener con él un contacto cotidiano, directo y de tipo familiar (GRUZINSKI, 1990). Ya he descrito los momentos más importantes que caracterizan las “misas" en el apartado dedicado a los devotos comunes, por lo tanto, ahora, concentraré la atención en las curaciones (que, en la mayoría de los casos, representan el momento final de la celebración de la misa), las cuales empiezan, siempre, con cantos y oraciones para propiciar la bajada del Niño Fidencio (que va evocada rezando colectivamente y utilizando los objetos purificadores arriba mencionados) en las materias, quienes, después, pueden realizar sus curaciones espirituales manipulando al enfermo. Junto con las materias, en estos rituales, están presentes las guardias, que representan los enfermeros que ayudan a la materia a realizar su curación. A continuación, dos breves descripciones de estos rituales de curación:

1) Yo veo todo en el agua. Sí, a veces tengo una guardia, a veces no tengo nada, a veces trabajo sola y no me pasa nada, gracias a Dios y al Niñito. En ratos me lleno de valor y en ratos me desmayo. Toda la gente que viene aquí es creyente. Por eso viene, porque tiene algunas necesidades entonces el Niñito es muy bueno para curar. Yo he curado hasta locos, se me sueltan y corren. (Fernanda, mujer, 64 años, devota y materia del Niño Fidencio desde hace 7 años).

2) Cuando voy a empezar a caminar con el niño o voy a hacer labor espiritual, 
mi ritual es hacer un rosario, primero que nada, purifico mi altar, ya después de que está purificado pongo sus fuentes de agua, sus veladoras, sus velones y empiezo a hacer el rosario, termino el rosario y empezamos a llamar al Niño, empezamos a realizar la bajada del Niño. El Niño baja y empieza a hacer su labor de curación espiritual (Pablo, hombre, 40 años, materia y devoto del Niño Fidencio desde hace 17 años)

Además de curar, las materias se encargan también de solucionar otros tipos de problemas cotidianos de sus devotos, y para lograr lo anterior, como siempre, tienen que comunicarse con el Niño Fidencio, quien, cuando es posible, ofrece a estas personas la solución de sus problemas:

Cuando, por ejemplo, viene alguien en busca de ayuda, consuelo o ayuda física o moral o personal, me plantean el problema y yo les digo que le preguntaremos al Niño y ya lo que el Niño marque vamos a hacer. Denme permiso de platicar con el Niño y ya conforme el platique conmigo les hago saber. A veces el Niño no me da la comunicación al momento, tenemos que esperar y humillarnos, inclinarnos ante mi Padre Dios para que el Niño venga y nos dé la solución de los problemas. Ya viene la gente en la tarde o al otro día y hay una respuesta, ya el Niño les dice va a pasar esto, se va a componer o de plano mi padre Dios no le da el permiso (Pablo, hombre, 40 años, materia y devoto del Niño Fidencio desde hace 17 años)

Los objetos y vestimentas que utilizan las materias durante los rituales de curación se mencionan en el siguiente testimonio:

Llevamos un gorrito que es como tipo militar. De hecho, eso yo no lo sabía hasta hace poco, que el tiempo del niño Fidencio era el de la revolución, entonces ese era como el gorrito que se usaba como tipo militar, entonces él lo usaba y se nos quedó como parte de su vestimenta. Usamos su capa, que casi siempre se usa para hacer la limpia de la persona. Llevamos una túnica, que es como para poder representar vaya a Jesús, porque el Niño se ponía una túnica y eso porque pues trataba de seguir los pasos de Jesús, entonces se quedó como parte de su vestimenta. La túnica lleva un cordón que va amarrado a la cintura, ese se usa también como protección tanto para el ser como para la persona. Dentro de eso pues se usa un crucifijo que es con el que el Niño daba las bendiciones a las personas que se acercaban y ya. Pues, de los demás elementos que se utilizan, pues, el principal es la loción, siempre se utiliza una loción para poder limpiar vaya, o sea para poder generar como un ambiente de armonía, debido al olor fresco, un olor rico que emite la loción. Gracias a la loción se genera un ambiente como que menos tenso y 
ya pues te permite limpiar más fácilmente a las personas (Roberto, hombre, 25 años, materia y devoto del Niño Fidencio desde hace 8 años).

La ropa utilizada, por lo tanto, tiende a reproducir la que usaba el Niño Fidencio. En este fragmento, entre otras cosas, es muy interesante destacar la conciencia del entrevistado de la dimensión sincrética (DE LA TORRE, 2012, pp. 509) de la devoción, elemento que la caracteriza desde sus inicios, es decir desde cuando el líder carismático estaba vivo y usaba, a propósito, cierto tipo de ropa, para "seguir los pasos de Jesús". Los objetos utilizados, además, tienen el objetivo de proteger y purificar, para poder realizar las curaciones en un ambiente "de armonía".

Pasando a los rituales individuales, vale la pena recordar que su objetivo principal es evocar y ponerse en contacto, de manera diaria, con el Niño Fidencio, como se puede apreciar en el próximo fragmento:

Yo, como materia, lo hago todas las noches. Primero le rezo, después platico con él. Existen unas alabanzas que son...como...alabanzas para poder evocar al niño Fidencio. Es la alabanza principal que nosotros usamos, de hecho, son alabanzas para llamar al Niño Fidencio, es la alabanza que, si se entona, ya es más fácil que el Niño pueda entrar en ti (Roberto, hombre, 25 años, materia y devoto del Niño Fidencio desde hace 8 años).

Un último elemento que es importante destacar en este apartado, y que forma parte de las vivencias cotidianas de los devotos y materias del Niño Fidencio en Saltillo, tiene que ver con las formas de intolerancia que los entrevistados experimentan, en sus vidas cotidianas, como consecuencia de sus creencias. Los principales sujetos que manifiestan actitudes intolerantes en contra de las creencias de nuestros entrevistados son sus mismos familiares y amigos pertenecientes al catolicismo, así como los sacerdotes católicos. Los actos a través de los cuales se expresan estas formas de intolerancia tienen que ver con formas de violencia simbólica, es decir aquel tipo de violencia que "afecta a la integridad moral de una persona sin alterar, sin embargo, directamente su participación en la vida social política o económica, cuando dicha violencia es del orden del desprecio, del prejuicio o de la simple expresión de odio, sin consecuencias sobre su integridad física" (WIEVIORKA, 2009, p. 87, traducción mía). A continuación, un ejemplo que se enfoca en la intolerancia experimentada por un entrevistado en su entorno familiar: 
Cuando el niño me escogió, mis amigos se retiraron. Ya no tenía amigos, después de tener muchos. Mi familia se molestó, como éramos católicos al $100 \%$ y el catolicismo no quiere al Niño, pues mi familia ya no quiso saber de mí. Pasaron 3 años para que mi familia me aceptara de nuevo. Llegó el día que quise "flaquear", es decir quise dejar al Niño, pero me arrepentí, le dije que no podía dejarlo porque si lo dejaba era como dejar la mitad de mí. Cuando empiezo a caminar con el Niño, mis hermanos me dejaron de hablar, éramos una familia muy unida, éramos una familia que para cualquier situación nos juntábamos y tratábamos de resolver los asuntos. Cuando empiezo a caminar con el Niño, mi papá se molestó mucho, me dijo que ya, para él lo del Niño no era bueno. Mis hermanos me dejaron de hablar. El más chiquillo era una persona que convivía mucho conmigo, él estaba conmigo y yo con él, me ayudaba en cualquier situación. Cuando él me dice, "mira ya no quiero que sigas en eso porque no es bueno", yo le dije: "bueno hermano si es lo que quieres yo lo voy a dejar, lo voy a hacer". Entonces me vine de mi casa angustiado, temeroso de lo que pasaría y pensando demasiado, llego a mi templo, a mi altar que solo era una mesa con tres imágenes, le dije al Niño que iba a cerrar las puertas de mi altar y en ese momento volteo a verlo y me doy cuenta que está conmigo. El Niño no me reprochó, no me dijo nada y me di cuenta que no era malo lo que yo estaba haciendo y dije pues no, no voy a cerrar el templo, no le voy a hacer caso a mi familia y voy a seguir con el Niño (Pablo, hombre, 40 años, materia y devoto del Niño Fidencio desde hace 17 años).

Aquí, como en otros casos, los familiares y amigos de los entrevistados no toleran la devoción hacia el Niño Fidencio porque, en cuanto católicos, la consideran algo malo, diabólico, una forma de brujería. Al mismo tiempo, vale la pena recordar que la ruptura con los familiares es una consecuencia muy típica de los procesos de conversión que, en la mayoría de los casos, implican "una ruptura (a veces dolorosa) con el entorno. Varios [conversos] expresan que fueron parcialmente rechazados por los suyos que no entendían su evolución” (LECAROS, 2017, p. 15). Los estereotipos que estas personas utilizan, para estigmatizar la devoción y los devotos del Niño Fidencio, se repiten en las narraciones de los entrevistados, como se puede apreciar también en el próximo fragmento:

Aquí, para los católicos, somos brujas. Creen que estamos mal de la cabeza, estamos equivocados y por eso dicen eso (Lucía, mujer, 39 años, devota del Niño Fidencio desde hace 5 años). 
En otras palabras, y concluyendo este apartado, todos los devotos entrevistados señalan que, en la sociedad saltillense, hay personas (familiares y amigos católicos) que tienden a difundir estereotipos (por ejemplo, como en el testimonio de arriba, definiéndolos brujos y locos) en contra de su devoción, los cuales, a través de más amplios mecanismos de estigmatización del Otro $^{16}$ (TAGUIEFF, 1999, p. 65), tienen como objetivo final deslegitimar (Chilton \& SCHÄFFNER, 2008, p. 306) sus creencias.

\section{Conclusiones provisionales: construyendo un modelo de las formas cotidianas de expresión de la devoción hacia el Niño Fidencio en Saltillo}

En este último apartado, presentaré algunas reflexiones conclusivas (pero provisionales), cuyo objetivo principal es construir un modelo flexible (BAGNASCO, 2009. p. XIII).) de las formas de expresión de la devoción hacia el Niño Fidencio, tanto de los devotos "comunes" como de las materias, en los espacios y tiempos cotidianos de sus existencias.

Vamos a empezar por los procesos a través de los cuales los entrevistados se volvieron (y decidieron seguir siendo) devotos y materias. Esos procesos, como en las conversiones religiosas, parece funcionar como un circuito complejo y dinámico que se desarrolla a través de diferentes dimensiones (GOOREN, 2010) o etapas ${ }^{17}$ (LOFLAND y STARK, 1965) que, tanto con respecto a los devotos "comunes" como a las materias, incluyen el primer encuentro con la devoción como consecuencia de un momento crítico en sus vidas, el momento del turning point, es decir cuando el Niño Fidencio favorece la solución del momento crítico, un periodo de experimentación de la devoción que los convence (por los milagros que los entrevistados experimentan en sus vidas) y un cambio de vida ${ }^{18}$ (como consecuencia de la elección de seguir siendo devotos y/o materias) que coincide con una mejora importante en las biografías de los entrevistados, con un pasaje de la “oscuridad a la luz" (BERGER y LUCKMANN, 2001, p. 198), en el sentido que, tanto para los devotos comunes como para las materias, implica una reorganización más amplias de sus existencias (HERVIEU-LÉGER, 2003, pp. 104-105).

\footnotetext{
16 En los cuales participan, también, los medios masivos de comunicación.

17 En todo caso, siempre concebidas de manera dinámica y flexible.

18 Como mencionado en el apartado 4, utilizando el modelo de Gooren (pp. 48-49), estas etapas coinciden con el pasaje de la preafiliación a la conversión (pasando por la afiliación).
} 
En cuanto a las prácticas cotidianas y concretas que caracterizan el ser devoto "común" y el ser materia del Niño Fidencio en Saltillo, es posible identificar, en ambos casos, dos diferentes tipos de actividades: las individuales y las colectivas. En cuanto a los devotos comunes, las actividades individuales tienen que ver con una relación cotidiana y personal que ellos tienen con el santo (mejor dicho, con las estatuas o imágenes que lo representan dentro de los altares domésticos), y que se concretiza a través de peticiones, oraciones y simplemente hablar ${ }^{19}$ con él todos los días, como si fuera un familiar (GRUZINSKI, 1990). También las materias se relacionan con el Niño Fidencio todos los días, evocándolo en sus domicilios, para fortalecer su relación con él y, también, para practicar el don que recibieron (y poderlo controlar cada vez más). En ambos casos, se trata de prácticas que se basan en una relación continua con el santo, vivida como parte importante de los momentos ordinarios de la vida cotidiana, en los espacios domésticos en los cuales viven los entrevistados.

Uno de los momentos colectivos principales que caracteriza las vivencias cotidianas de los devotos "comunes" y de las materias es, seguramente, la que ellos llaman "misa". Esta última, que se realiza en las casas de las materias presentes en Saltillo, tiene rasgos muy sincréticos (DE LA TORRE, 2012, pp. 509), en el sentido que algunos de los rituales que la caracterizan son tomados del catolicismo, pero con muchas diferencias. La principal diferencia es que, obviamente, el protagonista de la celebración en este caso es el Niño Fidencio (y no Jesús Cristo, como en las misas católicas), quien viene evocado para que al final realice, a través de las materias presentes, los rituales de curación. Los objetos más importantes utilizados en estos eventos son: flores, agua, lociones perfumadas, velas, incienso, todos elementos que tienen, como principal objetivo, purificar el ambiente para favorecer la bajada del santo en las materias. Otra importante actividad colectiva (que en la mayoría de los casos se realiza, como ya mencionado, durante las "misas") que efectúan las materias son los rituales de curación, los cuales consisten en propiciar la "bajada" del Niño Fidencio para curar, a través de operaciones espirituales, a las personas necesitadas. El santo viene evocado rezando, esparciendo lociones y aceites, prendiendo veladoras y utilizando, en general, el fuego y el agua, también en este caso, para purificar el lugar en el cual se realiza el ritual. Para celebrar sus "misas" y realizar las

19 Para contarle cosas, pedirle consejos o, simplemente, saludarlo y despedirse. 
curaciones, las materias se visten como el Niño Fidencio, es decir con una túnica (que puede ser blanca o roja y con una capa blanca, amarilla o morada), un cordón amarrado a la cintura, a veces una gorra militar, y un crucifijo.

Un último aspecto que caracteriza las maneras de vivir esta devoción en Saltillo, tanto de los devotos comunes como de las materias, es la intolerancia que los entrevistados dicen experimentar en las interacciones de sus vidas cotidianas. Estos actos de intolerancia son perpetrados, en la mayoría de los casos, por familiares y amigos católicos de los entrevistados y se expresan, principalmente, a través de formas de violencia simbólica (WIEVIORKA, 2009, p. 87), tales como ofensas, burlas, críticas, hasta llegar, en algunos casos, a la interrupción de las relaciones.

Sintetizando totos los elementos arriba mencionados, es posible afirmar que la devoción hacia el Niño Fidencio, en la vida cotidiana de los devotos y materias saltillenses, se basa en las dos siguientes tendencias generales: 1) el volverse devotos/materias del Niño Fidencio implica pasar por un proceso conformado por diferentes etapas, cuyo momento final consiste en un cambio de vida importante (y positivo) en las biografías de los entrevistados; 2) después, la devoción se vive a través de prácticas cotidianas, tanto individuales como colectivas, que se realizan en los ambientes domésticos de los actores involucrados y cuyas finalidades principales son mantener la relación familiar y continua con el santo y solucionar los problemas cotidianos (y prácticos) de salud (y de otro tipo) de los devotos.

Concluyendo, vale la pena destacar las dos principales aportaciones del presente estudio en el campo de estudios que se enfoca en las devociones populares. La primera es que esta investigación tiende a confirmar la capacidad de estas formas de expresión de la religiosidad de hacerse cargo de aquellas demandas de sentido, que las instituciones religiosas no quieren o no pueden satisfacer y, en el caso específico del fidencismo, de aquellas demandas cuyo objetivo principal es vivir bien aquí y ahora, en esta vida y en esta tierra. Esta última parece ser una necesidad cada vez más importante en el mercado de los bienes religiosos mexicano, como consecuencia, entre otros aspectos, del crecimiento constante de la "sensación de inseguridad [que las personas viven ${ }^{20}$ ] a cualquier hora del día" por el aumento de las

20 Principalmente para las personas más pobres y vulnerables, como en el caso de la mayoría de los devotos del Niño Fidencio, quienes, gracias a esta devoción, sostienen haber logrado superar algunos momentos críticos y haber desarrollado la capacidad de tener un mayor control sobre las cuestiones importantes en sus vidas (DE MARTINO, 2003; DE MARTINO, 2004). 
enfermedades, "de la delincuencia, el crimen, la corrupción y las pandemias" (PERDIGÓN, 2008, PP. 136-13721). En este contexto, entonces, el fidencismo representa una opción cada vez más competitiva (CHESNUT, 2003) y viable para cada vez más personas.

Otra interesante contribución del presente estudio es que se enfoca en un aspecto poco estudiado de las devociones populares, es decir su dimensión ordinaria y doméstica, en lugar de aspectos mucho más abordados en el campo de la sociología de las religiones tales como las peregrinaciones y fiestas patronales (rurales y urbanas). Esta dimensión ordinaria, doméstica y casi íntima, permite apreciar, entre otras cosas, la gran complejidad de este fenómeno, que parece penetrar en la mayor parte de los momentos cotidianos de la vida de los devotos.

Concluyendo, vale la pena recordar que los hallazgos encontrados en la presente investigación, en cuanto estudio de caso que se enfoca en un tema hasta ahora poco estudiado dentro de la sociología de las religiones, es decir las formas de expresión de la religiosidad popular en la vida cotidiana (AMMERMAN, 2013, p. XVI), pueden ofrecer un punto de referencia ${ }^{22}$ para futuras investigaciones cuyo objetivo sea analizar, al igual que en este texto, cómo se vive una devoción popular, además minoritaria ${ }^{23}$, en los momentos ordinarios de las vidas de sus devotos, es decir en aquellos tiempos y lugares que, a veces, tendemos a considerar poco importantes (tanto las personas en general como los investigadores) y en los cuales, en cambio, transcurrimos la mayor parte de nuestras existencias.

\section{Referencias}

AMMERMAN, N. Everyday Religion. Observing Modern Religious Lives. Nueva York, USA: Oxford University Press, 2007.

AMMERMAN, N. Introduction: Observing Modern Religious Lives. En: AMMERMAN, N. Everyday Religion. Observing Modern Religious Lives. Nueva York, USA: Oxford University Press, 2007.

${ }_{21}$ Quiero aclarar que las palabras de Perdigón se refieren, de manera específica, a la devoción hacia la Santa Muerte (otra devoción muy ligada al estar bien aquí y ahora) pero creo que se pueden adaptar también al fidencismo.

22 En palabras de Bagnasco; "una gran caja de herramientas que el investigador emplea encontrand y combinando instrumentos aptos a la comprensión de un caso concreto, que casi nunca corresponderá con las condiciones ideales de un modelo formal” (Bagnasco, 2009, p. XIII).

23 Aspecto que, entre otras cosas, se refleja en la cuestión de la intolerancia abordada en la parte final del apartado anterior. 
AMMERMAN, N. Sacred Stories, Spiritual Tribes: Finding Religion in Everyday Life. Nueva York, USA: Oxford University Press, 2013.

BAGNASCO, A. Presentazione. En: BOUDON R., Il posto del disordine. Bologna, Italia: Il Mulino, 2009.

BERGER P. L. y LUCKMANN T. La construcción social de la realidad. Argentina: Amorrortu Editores, 2001.

BERLANGA, J. L.; LARA, E.; RAMÍREZ, C. A. Las fiestas del dolor: un estudio sobre las celebraciones del Niño Fidencio. México: Consejo Nacional para la Cultura y las Artes, 1999.

BLUMER, H. Symbolic Interactionism. Perspective and Method. Berkeley, Los Angeles, London: University of California Press, 1986.

BOUDON, R. Subjective Rationality and the Explanation of Social Behavior. Rationality and Society vol. 1, n. 2, 171-196, 1989.

BOUDON, R. Il senso dei valori. Bologna, Italia: il Mulino, 2000.

BROMLEY, D. G. y PHILliPS, E. El Niño Fidencio. World Religions and Spirituality [versión electrónica]. Virginia Commonwealth University, USA, 2016, disponible en: https:// wrldrels.org/2016/10/08/el-nino-fidencio/. Consultado el: 31/07/2018.

CHESNUT, A. Competitive Spirits: Latin America's New Religious Economy. New York, USA: Oxford University Press, 2003.

CHILTON, P. y SCHÄFFNER, C. (2008). Discurso y política. En: VAN DIJK, T. A. El discurso como interacción social. Estudios sobre el discurso II. Una introducción multidisciplinaria. Barcelona, España: Gedisa, 2008.

CORBETTA, P. Metodología y técnicas de investigación social. Madrid, España: McGrawHill, 2007.

DE MARTINO, E. Sud e magia. Milano, Italia: Feltrinelli, 2003.

DE MARTINO, E. El mundo mágico, Buenos Aires, Argentina: Libros de la Araucaria, 2004.

DE LA TORRE, R. La religiosidad popular como "entre-medio" entre la religión institucional y la espiritualidad individualizada. Civitas - Revista de Ciências Sociais, 3, pp. 506-521, 2012.

GIORDAN, G. Introduction: The Varieties of Conversion Experience. En: GIORDAN, G.

Conversion in the Age of Pluralism. Leiden e Boston, USA: Brill, 2009.

GLASER B. G. y STRAUSS, A.L. The Discovery of Grounded Theory. Strategies for Qualitative Research, Chicago, USA: Aldine, 1967.

GOBO, G. Sampling, representativeness and generalizability. En SEALE, C., GOBO, G. GUbrium, J. F., SILVERMAN, D. Qualitative Research Practice, London: Sage Publications, 2007.

GOOREN, H. Religious Conversion and Disaffiliation. Tracing Patterns of Change in Faith Practices. New York, USA: Palgrave Macmillan, 2010.

GRAZIANO, F. Cultures of Devotion: Folk Saints of Spanish America. New York, USA: Oxford University Press, 2007.

GRUZINSKI, S. La guerra de las imágenes. De Cristóbal Colón a “Blade Runner” (14922019). México: Fondo de Cultura Económica, 1990. 
GUIDICINI, P. Manuale della ricerca sociológica. Milano, Italia: FrancoAngeli,1971.

HERVIEU-LÉGER D. Religione e memoria. Bologna, Italia: il Mulino, 1996.

HERVIEU-LÉGER, D. Il pellegrino e il convertito. La religione in movimento. Bologna, Italia: il Mulino, 2003.

JEDLOWSKI, P. Un giorno dopo l'altro. La vita quotidiana fra esperienza e routine. Bologna, Italia: il Mulino, 2005.

LECAROS, V. Estudios de recorridos religiosos: los desafiliados en contexto. Estudos de Religião, 31, 3, pp. 1-20, 2017.

LOFLAND, J. y STARK R. Becoming a World-Saver: A Theory of Conversion to a Deviant Perspective. American Sociological Review, 6, pp. 862-875, 1965.

LOFLAND, J. y SKONOVD, N. Conversion Motifs, in «Journal for the Scientific Study of Religion», 20, 4, pp. 373-385, 1981.

MCGUIRE, M. B. Lived Religion. Faith and Practice in Everyday Life. Oxford, UK: Oxford University Press, 2008.

NESTI, A. Gesù socialista. Una tradizione popolare italiana. Torino, Italia: Claudiana, 1974.

NESTI, A. Il cattolicesimo degli italiani. Religione e culture dopo la secolarizzazione. Milano, Italia: Guerini e Associati, 1997.

PACE, E. La falesia e il compasso. Riflessioni sulla permanenza e universalità della religiosità popolare. En: BERZANO, L., CASTEGNARO, A., PACE, E. Religiosità popolare nella società post-secolare. Nuovi approcci teorici e nuovi campi di ricerca. Padova, Italia: Edizioni Messaggero, 2014.

PERDIGÓN, K. La Santa Muerte protectora de los hombres. Ciudad de México, México: INAH, 2008.

PRANDI, C. Religione e classi subalterne. Roma, Italia: Coines, 1977.

QUIROS, G. F. El Niño Fidencio y el fidencismo. Monterrey, México: Editorial Font, 1991.

RAMÍREZ, J. La religiosidad popular en la identidad cultural latinoamericana y caribeña. En: QUEZADA, N. Religiosidad popular México-Cuba. México: Plaza y Valdés-UNAM, 2004.

SILVERMAN, D. y MARVASTI, A. Doing Qualitative Research. A Comprehensive Guide. USA: Sage Publications, 2008.

TAGUIEFF, P. A. Il razzismo. Pregiudizi, teorie, comportamenti. Milano, Italia: Raffaello, 1999.

WIEVIORKA, M. E1 racismo: una introducción. Barcelona, España: Gedisa, 2009.

ZaVAletA, A. El Niño Fidencio and the Fidencistas, Zellner. En: PETROWSKY, M. Sects, Cults, and Spiritual Communities: A Sociological Analysis. Westport, CT: Praeger, 1998.

ZAVALETA, A.; SALINAS, A.; SAMS, J. Curandero Conversations: El Niño Fidencio, Shamanism and Healing Traditions of the Borderlands. Bloomington, IN: AuthorHouse, 2009.

Submetido em: 25-6-2019

Aceito em: 11-5-2020 